\title{
Organic Molecular Weaves
}

\author{
Andreas Herdlitschka, Bartosz Lewandowski, and Helma Wennemers*
}

\begin{abstract}
Weaving of organic compounds on the molecular level is an intriguing challenge and promises to provide materials that combine high elasticity with strength and fracture toughness. Yet, the formation of crossing points between molecular threads in defined and regular distances to create an interwoven network is not trivial. To date, only a few examples of wholly organic weaves have been reported. Within this review we present the different strategies that enabled their formation and highlight the structural features of the obtained nanostructured materials. We expect these pioneering studies to pave the way to many more organic molecular weaves with more and more sophisticated topologies and exquisite mechanical properties.
\end{abstract}

Keywords: Molecular Weaves · Nanostructured materials · Supramolecular Chemistry · Topologies

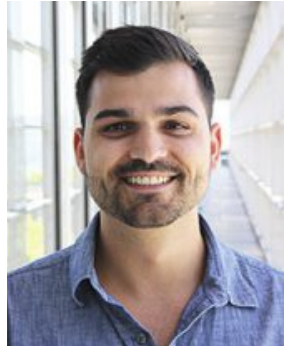

Andreas Herdlitschka received his Bachelor degree in chemistry from the Technical University of Munich. Afterwards he moved to Marburg for his Masters studies to specialize in medicinal chemistry. For his Masters thesis he joined the group of Prof. Helma Wennemers at the ETH Zurich, where he discovered his passion for supramolecular chemistry. After receiving his Masters degree in chemistry from the Philipps-University of Marburg he joined the group of Prof. Helma Wennemers for his $\mathrm{PhD}$ studies to investigate oligoprolinechromophore-conjugates towards novel supramolecular architectures and materials.

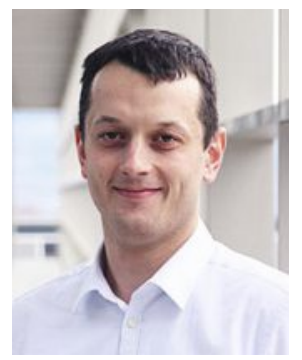

Bartosz Lewandowski received his MSc Eng. degree in Chemistry from Warsaw University of Technology in 2004. For his $\mathrm{PhD}$ studies he joined the group of Prof. Sławomir Jarosz at the Institute of Organic Chemistry, Polish Academy of Sciences, where he worked on the synthesis and recognition properties of sucrose-based macrocyclic receptors. In 2009 he moved to Edinburgh, UK, for a post-doctoral research stay with Prof. David Leigh in the field of artificial molecular machines. In 2013 he was awarded the Marie Skłodowska-Curie individual fellowship to join the group of Prof. Helma Wennemers at the ETH Zurich. In 2016 he was appointed as a Senior Scientist in the Wennemers Group. His research focuses on peptide and carbohydrate-based functional supramolecular assemblies.

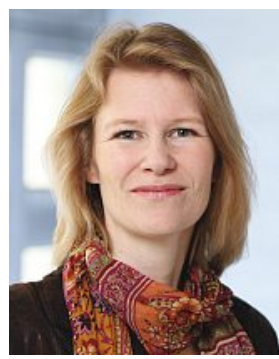

Helma Wennemers studied chemistry at the Goethe-University in Frankfurt and received her PhD degree from Columbia University, New York for research with Prof. W. Clark Still. After postdoctoral studies with Prof. Hisashi Yamamoto at Nagoya University she joined Basel University as the Bachemendowed Assistant Professor. In the fall of 2011 Helma moved to ETH Zurich where

${ }^{*}$ Correspondence: Prof. H. Wennemers

E-mail: helma.wennemers@org.chem.ethz.ch

Laboratorium für Organische Chemie, ETH Zurich, D-CHAB, Vladimir-Prelog-Weg 3, $\mathrm{CH}-8093$ Zürich she is Professor of Organic Chemistry. Her research focuses on asymmetric catalysis, chemical biology, and synthetic materials. This scope includes the development of peptidic catalysts, functionalizable collagen, and molecular scaffolds for applications in supramolecular and biological chemistry (e.g. cell-penetrating peptides, and tumor targeting) as well as the controlled formation of metal nanoparticles.

\section{Introduction}

Humans began to weave organic fibers into textiles at least 26,000 years ago. ${ }^{[1]}$ The nanoscale application of this Stone Age art has the promise of creating versatile new materials for modern society. Yet, despite tremendous advancements in the field of supramolecular chemistry in the last decades - including the development of numerous nanostructured materials ${ }^{[2-6]}$ and discrete assemblies with sophisticated molecular topologies ${ }^{[7-11]}$ - the weaving of wholly organic molecules into extended structures is in its infancy. Weaving on the molecular level is difficult since looms are missing to install crossing points with an up-and-down geometry of entwining threads. ${ }^{[12]}$ Even interlacing with the help of metal complexes, which provide for defined directionality and therefore predictable cross-over geometries, has proven challenging. ${ }^{[13-20]}$ Diaxial weaves are most common in textiles and are composed of two interwoven sets of threads ('warp' and 'weft') that are often oriented at an angle of $90^{\circ}$ to each other (Fig. 1A). Advanced weaves that involve more than two sets of threads provide macroscopic objects with higher stability[21] but are more difficult to access (Fig. 1B). Recently, the first fully organic extended molecular weaves have been accomplished. ${ }^{[22-26]}$ Herein, we review the 'molecular loom strategies' that enabled these achievements and highlight the properties of the obtained nanostructured materials.

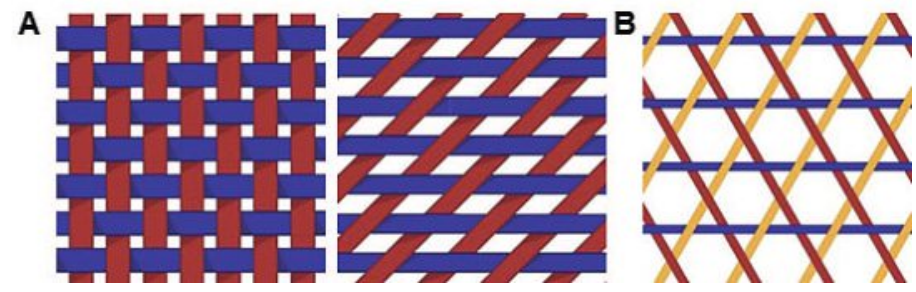

Fig. 1. Illustration of $A$ ) diaxial weaves composed of two interwoven sets of threads ('warp' and 'weft') and B) advanced weave with three sets of threads. 
Fig. 2. Synthesis and structure of COF-505: A) Cu(I)-ions coordinate to phenanthroline (PDB) ligands in a close-to-tetrahedral geometry; Upon imine formation with the homo-bifunctional benzidine (BZ) linkers, interwoven PDB-BZ threads form. B) 2-folded interpenetrating COF-505 structure in its metallated state; C) Arrangement of adjacent organic ligands in the crystal structure of COF-505, propagating at $57^{\circ}$ angles with $\mathrm{Cu}(\mathrm{l})$-ions as the points of registry; D) Neighboring blue helices are woven with the orange helices to form the overall framework; E) TEM image of a single sub- $\mu$ m crystal used for 3D-EDT analysis; F) HRTEM image of COF-505. (reproduced and modified from ref. [22] with permission from Science)

\section{Covalent Molecular Weaves}

\subsection{Metal Complexes as Crossing Points}

In 2016, Yaghi and coworkers achieved the formation of a molecular weave, which consists of two interlaced threads, by using metal complexes as templates for the formation of crossing points (COF-505, Fig. 2). ${ }^{[22]}$ The researchers equipped bidentate phenanthroline ligands with two aldehyde moieties and formed $\mathrm{Cu}$-complexes with a nearly tetrahedral geometry (Fig. 2A). Reaction of the aldehydes with benzidine bearing two amino groups in the para-positions connected the $\mathrm{Cu}$-complexes via imine bonds to form interlaced molecular threads. The geometry of the tetrahedral metal complexes combined with the rigidity of the benzidine linker ensured the directionality and up-and-down geometry of the diaxially interlaced threads (Fig. 2B). Fouriertransform infrared spectroscopy (FT-IR) and solid-state nuclear magnetic resonance (NMR) spectroscopy analyses confirmed the formation of imine-bonds. Single crystal X-ray diffraction (Fig. 2C/D), 3D electron diffraction tomography (3D-EDT), powder $\mathrm{X}$-ray diffraction (PXRD), and high-resolution transmission electron microscopy (HR-TEM, Fig. 2F) analyses of the crystalline product support a 2 -fold interpenetrating woven 3D-network with a distorted tetrahedral geometry around the $\mathrm{Cu}(\mathrm{I})$ center and a dihedral angle of $57^{\circ}$ between the phenanthroline ligands (Fig. 2B). Washing of the metal-coordinated framework with an aqueous $\mathrm{KCN}$ solution removed the $\mathrm{Cu}(\mathrm{I})$-ions and yielded a fully-organic extended molecular weave. This demetalation increased the elasticity of the material by ten-fold as evidenced by the measured Young's moduli before $(1.3 \mathrm{GPa})$ and after $(\sim 12.5 \mathrm{GPa})$ removal of the $\mathrm{Cu}$-ions. Remetalation of the woven framework restored the original elasticity parameters.

$\mathrm{BF}_{4}$ anions served as the counterions for $\mathrm{Cu}(\mathrm{I})$ in this initial diaxial weave. When the sterically more demanding $\mathrm{PO}_{2} \mathrm{Ph}_{2}$ anion was used as counterion, Yaghi obtained an interwoven structure with the same topology but larger pores. [23] The larger counterions also prevented interpenetration of the threads and thus provided for pores large enough to host guests such as THF and organic dyes (e.g. methyl orange, hydroxynaphthol blue and methyl blue). Upon using hexacoordinate $\mathrm{Co}$ (II) instead of tetracoordinate $\mathrm{Cu}(\mathrm{I})$ as the templating metal, the group formed a non-interpenetrating, diaxially woven framework (COF-112) with interlaced threads that cross at an angle of $77.3^{\circ}$ (Fig. 3). [24]

The above examples demonstrate the value of metal complexes with a defined geometry as crossing points followed by their covalent tethering for the formation of organic woven materials.
A

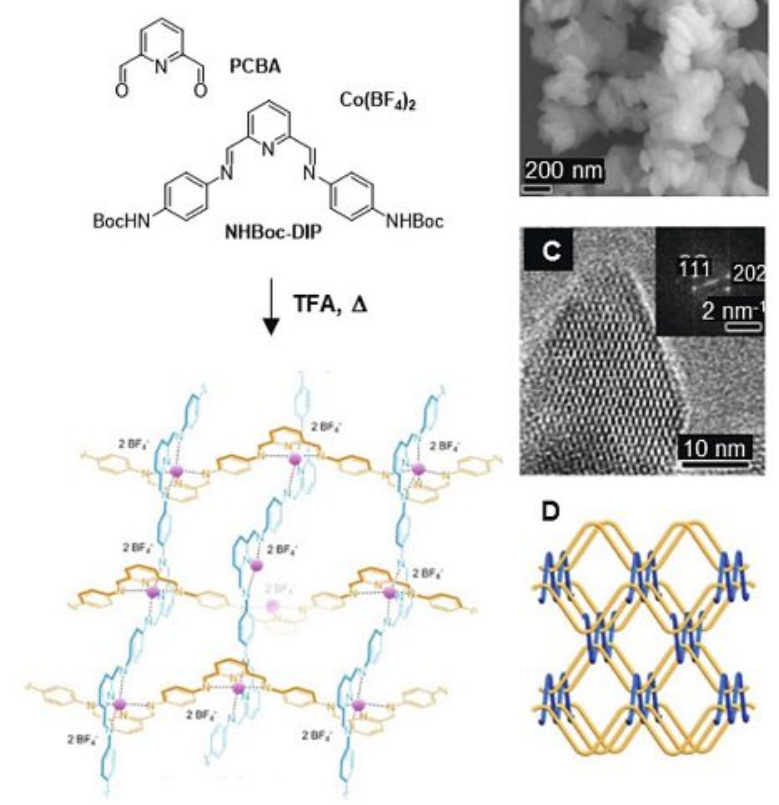

Fig. 3. A) Synthesis of diaxially woven COF-112 with a set of threads crossing at $77.3^{\circ}$; (B) SEM image of COF-112 crystals; (C) HRTEM image of the woven material; (D) model of the woven framework of COF112. (reproduced and modified from ref. [24] with permission from The Journal of the American Chemical Society)

They show that small modifications of the reaction partners, e.g. the metal complex or counterion, can affect the structure of the resulting woven material to a significant extent.

\subsection{Layered Metal Organic Frameworks for Molecular Weaving}

Whereas Yaghi employed metal complexes to install crossing points, a team led by Mayor and Wöll used metal complexes to preorganize ligands with reactive moieties to form crossing points upon covalent bond formation. ${ }^{[25]}$ The researchers used quadritopic cross-shaped building blocks that bear at two opposite sites carboxylic acid moieties and at the other two sites alkyne moieties as reactive groups for Glaser coupling reactions (Fig. 4, top left). Upon deposition on a gold surface, the $\mathrm{CO}_{2} \mathrm{H}$ groups of four building blocks formed square planar complexes with $\mathrm{Cu}(\mathrm{I})$ ions, which resulted in a regular grid-like 2D metal 

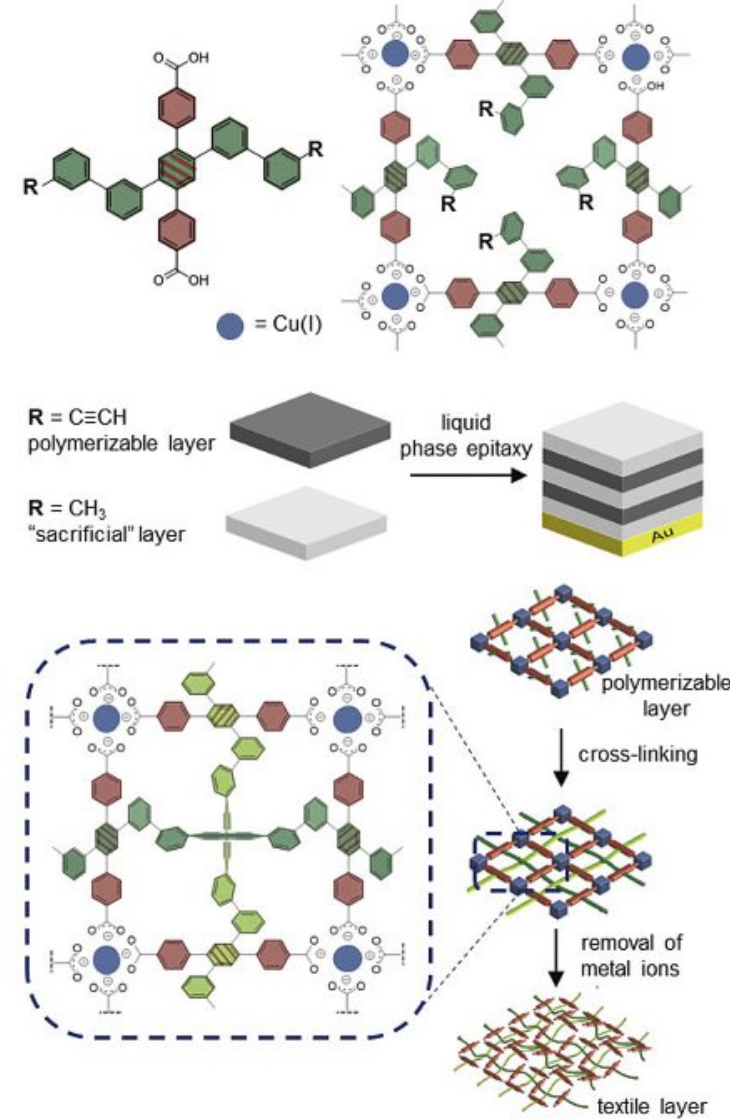

Fig. 4. Molecular structure of the polymerizable and non-polymerizable building blocks and their assembly by coordination to $\mathrm{Cu}(\mathrm{l})$-ions into a square unit. Liquid phase epitaxy to form alternating polymerizable and 'sacrificial' layers. Formation of crossing points within the polymerizable MOF layer by Glaser reactions and removal of the metal ions. (reproduced and modified from ref. [25] with permission from Nature Communications.)

organic framework (MOF) layer (Fig. 4, top middle). The sterically constrained biphenyl backbone of the building blocks positions the alkyne moieties opposite to each other within the layer. To enforce reaction between alkynes within one layer, the researchers placed non-polymerizable ('sacrificial') layers that bear methyl in place of alkyne groups between the polymerizable layers (Fig. 4, top right). This sandwich-like assembly of alternating polymerizable and non-polymerizable MOF-layers was achieved by liquid-phase epitaxy, a method that involves the layer-by-layer deposition of material on a surface through soaking-cycles in solutions with the desired molecular components (Fig. 4).

Covalent bond formation was achieved by immersing the multilayer assembly in a solution of tetramethylenediamine (TMEDA)- $\mathrm{CuCl}$ under an oxygen atmosphere (Glaser-Hay coupling). The constraints of the biphenyl moieties require the reacting alkyne of a given ligand to bend out of plane of the layer. The complementary covalent bond within one square can therefore only form when the perpendicular alkynes bend into the opposite direction of the plane. As a result, an alternating up-and-down geometry of molecular threads forms with consecutive GlaserHay couplings and establishes crossing points within a diaxial weave (Fig. 4).

Infrared reflection absorption spectroscopy (IRRAS) and Raman spectroscopy showed a characteristic vibrational band of the diacetylene-group and confirmed the formation of the GlaserHay product. SEM and AFM images showed planar material that extends into the nanometer regime (Fig. 5A) with a thickness of $\sim 20 \mathrm{~nm}$ (Fig. 5B,C).

Fewer cycles during the liquid-phase epitaxy reduced the number of layers in the assembly and the thickness of the obtained material. Demetalation was achieved by treatment of the assembly with dilute aqueous hydrochloric acid. Ultrasonication in THF disassembled the network into discrete $4 \mathrm{~nm}$ thick and $200 \mathrm{~nm}$ long polymeric fibers as revealed by AFM analysis (Fig. 5D-F). These dimensions are close to those expected based on the molecular dimensions and assembly mode of the components. The observed fibers are therefore a strong support for the formation of the woven structure.

The bottom-up layer-by-layer assembly is an ingenious approach to extended woven materials that cleverly uses molecular constraints to generate interlaced threads. The strategy relies on the quantitative formation of covalent bonds, ideally propagating from one starting point through the polymerizable MOF layer features that might be difficult to control.

\section{A Non-covalent Molecular Weave}

\section{1 $\pi-\pi$ and $\mathrm{CH}-\pi$ Interactions between Peptide- Chromophore Conjugates to Establish Crossing Points}

The two above-described approaches require the efficient formation of defined covalent bonds upon crosslinking of the metal-coordinated building blocks. The correction of errors is difficult if not impossible when threads with non-reversible covalent bonds form the weave. In 2017 our group used an oli-
Fig. 5. (A) SEM image of 5 cycles of molecular weaving attached on TEM grids; (B) AFM image and $(C)$ height profile of 5 cycles of molecular weaving attached on a smooth silica substrate; (D) Schematic illustration of the disassembly of the molecular weave; (E) AFM images of the single chain polymer after disassembly; (F) height profile of the single chained polymer. (reproduced and modified from ref. [25] with permission from Nature Communications)
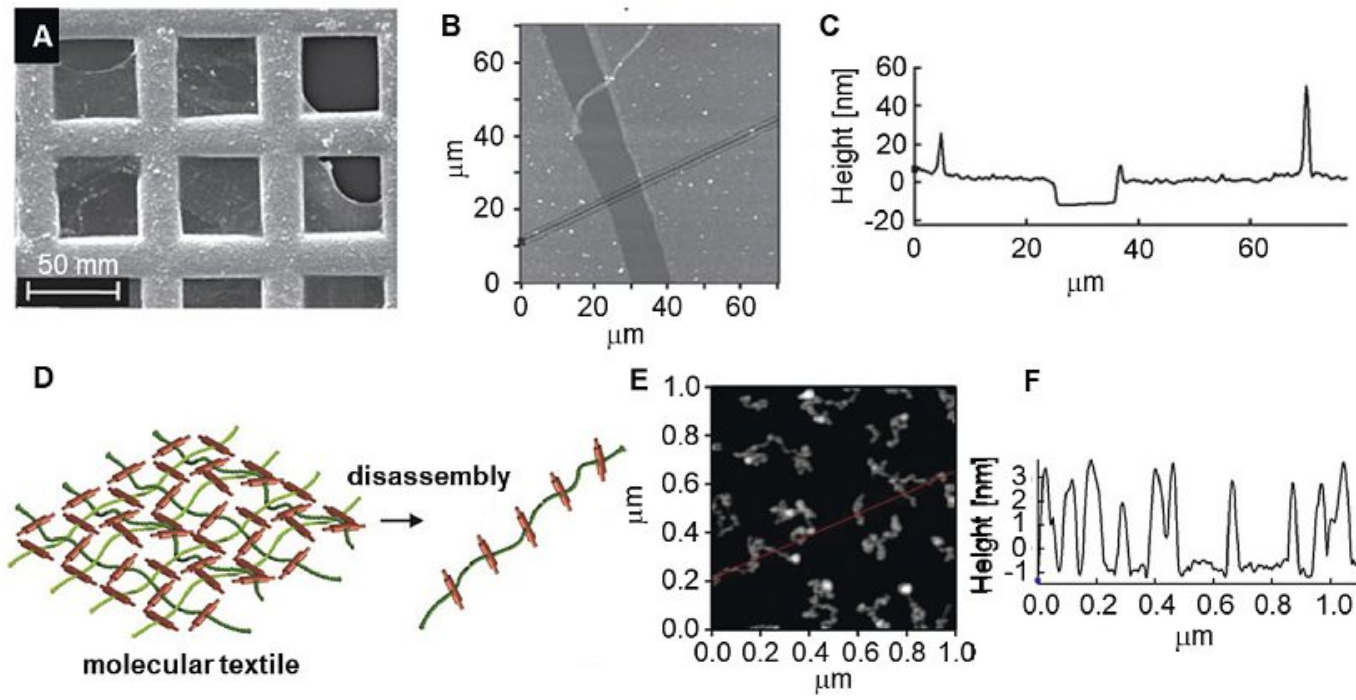

$\mathbf{F}$

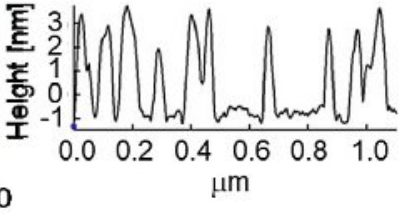


A
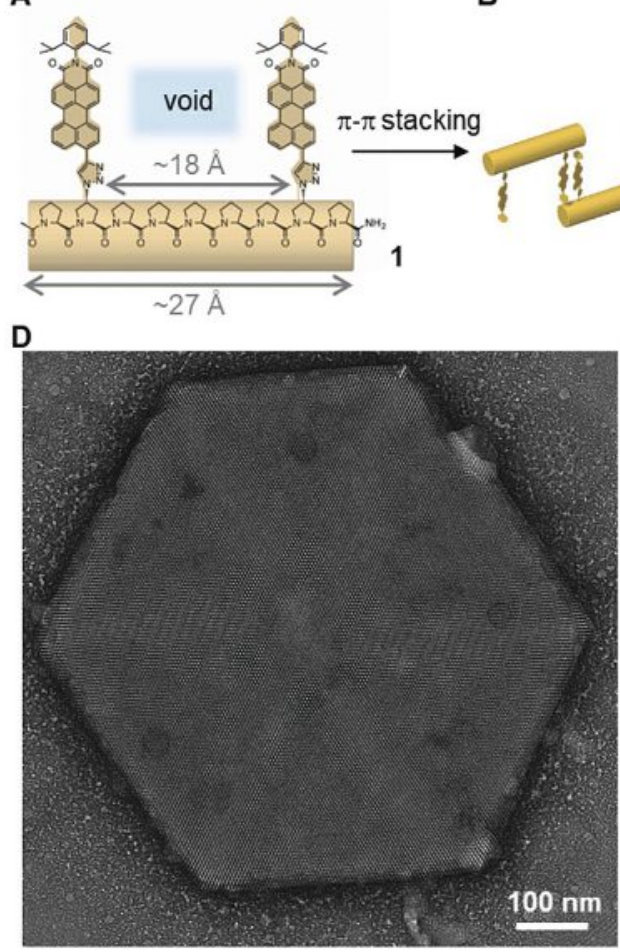

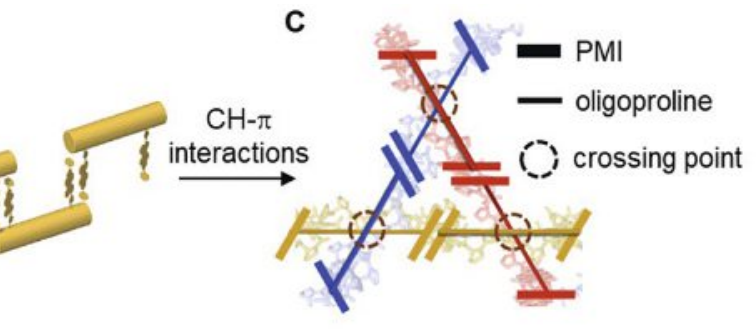

E

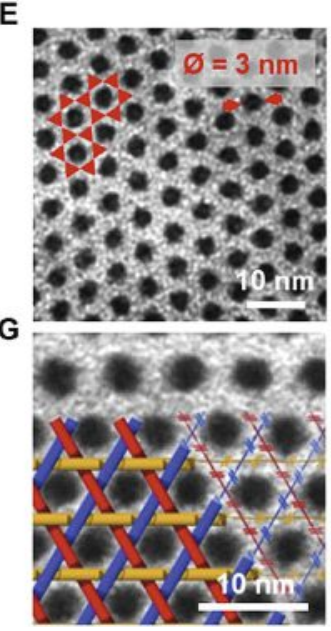

$F$

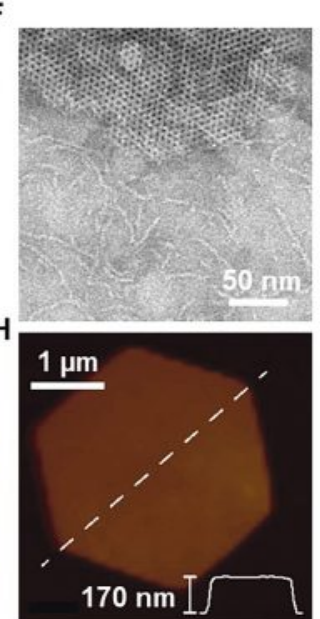

Fig. 6. (A) Molecular structure of the oligoproline conjugate 1; (B) Self-assembly of $\mathbf{1}$ into threads and (C) triangular connecting points to form a triaxial weave; (D) TEM micrograph of selfassembled $\mathbf{1}$ at low and $(E)$ higher magnification formed at $50 \mu \mathrm{M}$ in THF: $\mathrm{H}_{2} \mathrm{O}$ (30:70); (F) TEM micrograph of 1 at $500 \mu \mathrm{M}$ in THF: $\mathrm{H}_{2} \mathrm{O}$ (30:70); (G) Illustration of the molecular organization of the woven topology superimposed on the TEM micrograph; (H) AFM micrograph with height profile. goproline-chromophore conjugate to form a triaxial molecular weave that is held together by non-covalent $\pi-\pi$ stacking and $\mathrm{CH}-\pi$ interactions. ${ }^{[26]}$ The woven material is thus formed under thermodynamic control and errors are corrected in the formation process.

Building on prior supramolecular assemblies of oligoprolinechromophore conjugates, ${ }^{[27-29]}$ we installed perylene monoimide (PMI) moieties via triazole linkages at the two penultimate positions of a rigid oligoproline 9-mer ( 1 in Fig. 6A). This design ensured that the two PMI moieties point in the same direction ${ }^{30]}$ with a void of $\sim 18 \AA$ between them. It also ensured that conjugate 1 can self-assemble, similarly to related conjugates, ${ }^{[27-29]}$ head-to-tail by $\pi-\pi$ stacking of the PMI moieties into threads (Fig. $6 \mathrm{~B})$. Upon annealing in a mixture of $30 \%$ THF in $\mathrm{H}_{2} \mathrm{O}$, conjugate 1 formed hexagonal plates with dimensions in the micrometer regime (Fig. 6D). TEM analyses revealed a highly regular structure that consists of triangles with high electron density and hexagonal holes with diameters of $\sim 3.0 \mathrm{~nm}$ (Fig. 6E,G). AFM analyses of more than 150 superstructures revealed that the hexagons are flat (Fig. $6 \mathrm{H}$ ) and have average widths of $3.02 \pm 0.91 \mu \mathrm{m}$ and heights of $179 \pm 55 \mathrm{~nm}$. TEM images, which were recorded from samples at higher concentration (500 instead of $50 \mu \mathrm{M}$ ), supported the formation of threads that further assemble into the hexagonal superstructures (Fig. 6F). Together with UV-Vis and CD spectroscopy as well as X-ray powder diffraction (GIWAXS) the microscopic data provided detailed insight into the assembly: The self-assembled threads have up-and-down facing voids (Fig. 6B) that are filled by intercalation with two additional threads at an angle of $60^{\circ}$ (Fig. 6C). As a result, triangular connecting points form, which are stabilized by the $\pi-\pi$ stacking along the threads and weaker $\mathrm{CH}-\pi$ interactions between chromophore pairs of the interwoven threads. The molecular dimensions of this supramolecular assembly of conjugate $\mathbf{1}$ match perfectly the dimensions observed in the microscopic images (Fig. 6G).

Thermal annealing and monitoring of the self-assembly of molecularly dissolved conjugate $\mathbf{1}$ upon cooling by UV-Vis spectroscopy revealed a sharp transition at $51{ }^{\circ} \mathrm{C}$ from the non-assembled to the assembled state, which is indicative of a cooperative nucleation-elongation self-assembly mode (Fig. 7A). Fitting of the data to the Eikelder-Markvoort-Meijer model[31] allow to determine that the initial nucleus is composed of 10 molecules the number necessary to form two adjacent triangular connection points (Fig. 7B) - suggesting that this is the minimal nucleus for the propagation of the molecular weave.

Weaving bestows macroscopic objects with mechanical stability. The determination of Young 's moduli by quantitative nanomechanical mapping (QNM) showed that also the triaxially woven material is stiffer $(1.7 \mathrm{GPa})$ compared to non-woven
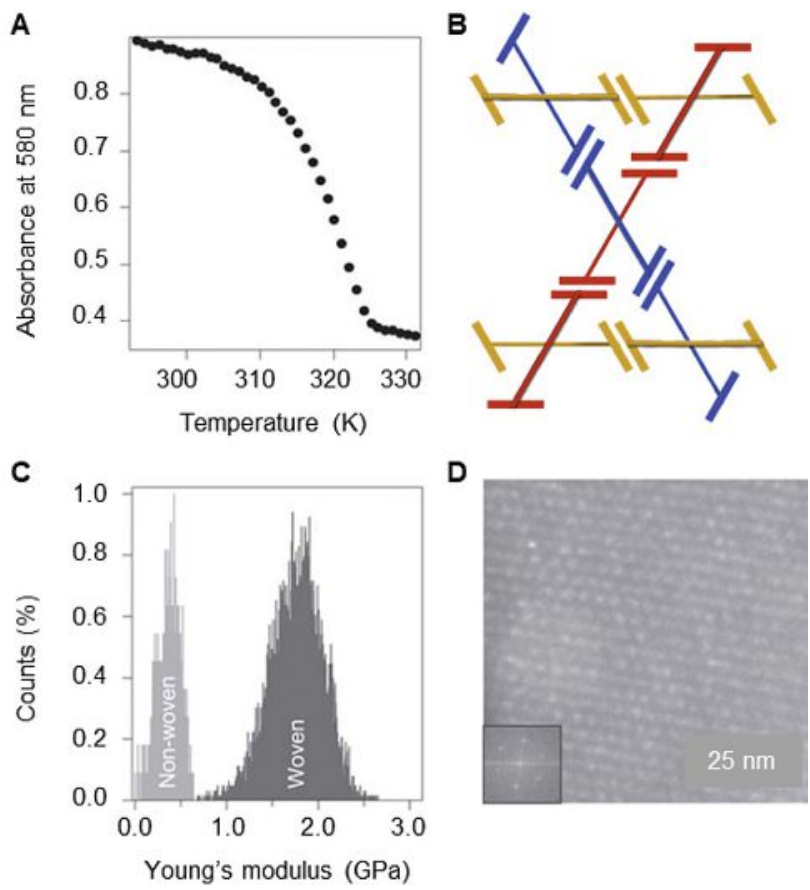

Fig. 7. (A) Temperature-dependent UV-Vis absorption at $580 \mathrm{~nm}$ of 1 (30:70 THF: $\mathrm{H}_{2} \mathrm{O}, 50 \mu \mathrm{M}$ ); (B) Proposed structure of the 10-molecule selfassembly nucleus; (C) Comparison of Young's modulus of woven (dark grey) and non-woven (light grey) 1 by PeakForce QNM; (D) Unstained dark-field STEM micrograph of IrNPs embedded in the holes of selfassembled 1 (dropcast from toluene suspension). Inset: Fast Fourier transform (FFT) analysis of the micrograph with the regular hexagonal arrangement of IrNPs. 
threads (0.3 GPa, Fig. 7C). In addition, the woven material is so strong that it withstands multiple cycles of lyophilization and redispersion in different solvents, including water and toluene. Thus, despite the lack of covalently tethered threads, it is the woven topology, achieved by the synergistic interplay of noncovalent interactions that endows the supramolecular assembly with remarkable robustness. In addition, the uniformly shaped pores of the triaxial weave allowed for the formation of homogeneously sized iridium nanoparticles with a diameter of $3 \mathrm{~nm}$ inside the holes (Fig. 7D). Thus, the pores of the triaxial weave can serve as templates for guest molecules, a finding that opens exciting perspectives for applications such as catalysis, sensing, or separation and storage.

\section{Conclusions and Outlook}

The few examples of wholly organic weaves that have emerged since 2016 highlight the prospects of weaving on the molecular level for the development of materials that combine features such as elasticity and robustness. Three unique approaches have so far been used as 'chemical looms'. They rely either on the formation of metal complexes followed by covalent cross-linking of the ligands and demetalation, or the self-assembly of building blocks that are preorganized to form threads and interweave with each other. The interactions that hold the threads together (covalent bonds or intermolecular interactions) are stronger compared to those responsible for the intertwining of the threads to form the weave. Since the design of molecular weaves - even of the simplest with diaxial connecting points - is difficult, serendipitous discoveries will likely accompany the path to more and more elaborate woven topologies. The practitioners in the field enjoy the challenge of creating complex molecular architectures for the development of materials with exquisite properties. Already the initial examples showed that molecular weaves are valuable for their elasticity and robustness as well as for the incorporation of molecular guests and even the synthesis of objects on the nanoscale inside pores - findings that could be useful for storage and delivery. In light of the numerous macroscopic woven materials that have been developed and appreciated by mankind over the past thousands of years for practical purposes (e.g. fishing nets, baskets, clothes) as well as for their beauty and esthetics, the future of materials woven on the nanoscale - a field that is in its infancy - is bright and an exciting arena of research.

Received: May 23, 2019

[1] O. Soffer, J. M. Adovasio, D. C. Hyland, 'Perishable Technologies and Invisible People: Nets, Baskets, and "Venus" Wear ca. 26,000 B.P.' in 'Enduring Records: The Environmental and Cultural Heritage of Wetlands', Ed. B. A. Purdy. Oxford, Oxbow Books, 2001, p. 233.

[2] W. Zhang, W. Jin, T. Fukushima, A. Saeki, S. Seki, T. Aida, Science 2011, 334, 340, DOI: 10.1126/science. 1210369 .

[3] H. Dietz, S. M. Douglas, W. M. Shih, J. H. Reif, T. H. LaBean, H. Yan, Science 2009, 325, 725, DOI: 10.1126/science.1174251.

[4] Z. Yu, F. Tantakitti, T. Yu, L. C. Palmer, G. C. Schatz, S. I. Stupp, Science 2016, 351, 497, DOI: 10.1126/science.aad4091.

[5] J. Malo, J. C. Mitchell, C. Vénien-Bryan, J. R. Harris, H. Wille, D. J. Sherratt, A. J. Turberfield, Angew. Chem. Int. Ed. 2005, 44, 3057, DOI: 10.1002/ anie. 200463027
[6] P. A. Korevaar, S. J. George, A. J. Markvoort, M. M. J. Smulders, P. A. J. Hilbers, A. P. H. J. Schenning, T. F. A. De Greef, E. W. Meijer, Nature 2012 481, 492, DOI: 10.1038/nature 10720

[7] N. Ponnuswamy, F. B. L. Cougnon, J. M. Clough, G. D. Pantoş, J. K. M. Sanders, Science 2012, 338, 783, DOI: 10.1126/science.1227032.

[8] K. S. Chichak, S. J. Cantrill, A. R. Pease, S.-H. Chiu, G. W. V Cave, J. L. Atwood, J. F. Stoddart, Science 2004, 304, 1308, DOI: 10.1126/science. 1096914

[9] G. Gil-Ramírez, D. A. Leigh, A. J. Stephens, Angew. Chemie Int. Ed. 2015, 54, 6110, DOI: 10.1002/anie.201411619.

[10] S. D. P. Fielden, D. A. Leigh, S. L. Woltering, Angew. Chemie Int. Ed. 2017, 56, 11166, DOI: 10.1002/anie.201702531.

[11] J. J. Danon, A. Krüger, D. A. Leigh, J.-F. Lemonnier, A. J. Stephens, I. J. Vitorica-Yrezabal, S. L. Woltering, Science 2017, 355, 159, DOI: 10.1126/ science.aal1619.

[12] a) P. Payamyar, B. T. King, H. C. Öttinger, A. D. Schlüter, Chem. Commun. 2016, 52, 18, DOI: 10.1039/C5CC07381B. b) M. Servalli, H. C. Öttinger, A. D. Schlüter, Physics Today 2018, 72, 40.

[13] Pamela M. Van Calcar, and Marilyn M. Olmstead, A. L. Balch, Inorg. Chem. 1997, 36, 5231, DOI: 10.1021/IC970269S.

[14] Y.-H. Li, C.-Y. Su, A. M. Goforth, K. D. Shimizu, K. D. Gray, M. D. Smith H.-C. zur Loye, Chem. Commun. 2003, 1630, DOI: 10.1039/B303708H.

[15] L. Carlucci, G. Ciani, A. Gramaccioli, D. M. Proserpio, S. Rizzato, CrystEngComm 2000, 2, 154, DOI: 10.1039/B006306L.

[16] A. M. Champsaur, C. Mézière, M. Allain, D. W. Paley, M. L. Steigerwald, C. Nuckolls, P. Batail, J. Am. Chem. Soc. 2017, 139, 11718, DOI: 10.1021/ jacs.7b07279.

[17] I. Enos A. Axtell, J.-H. Liao, M. G. Kanatzidis, Inorg. Chem. 1998, 37, 5583, DOI: 10.1021/IC980360B.

[18] T. Bark, M. Düggeli, H. Stoeckli-Evans, A. von Zelewsky, Angew. Chem. Int. Ed. 2001, 40, 2848, DOI: 10.1002/1521-3773(20010803)40:15<2848::AID ANIE2848>3.0.CO;2-S

[19] P. M. V. Calcar, M. M. Olmstead, A. L. Balch, Chem. Commun. 1995, 1773, DOI: $10.1039 / \mathrm{C} 39950001773$

[20] F. L. Thorp-Greenwood, A. N. Kulak, M. J. Hardie, Nat. Chem. 2015, 7, 526, DOI: $10.1038 /$ nchem. 2259.

[21] T. Tyler, 'Developments in Triaxial Woven Fabrics', in 'Specialist Yarn and Fabric Structures: Developments and Applications', Ed. R. H. Gong, Woodhead, 2011, chap. 7.

[22] Y. Liu, Y. Ma, Y. Zhao, X. Sun, F. Gándara, H. Furukawa, Z. Liu, H. Zhu, C. Zhu, K. Suenaga, P. Oleynikov, A. S. Alshammari, X. Zhang, O. Terasaki, O. M. Yaghi, Science 2016, 351, 365, DOI: 10.1126/science.aad4011.

[23] Y. Liu, Y. Ma, J. Yang, C. S. Diercks, N. Tamura, F. Jin, O. M. Yaghi, J. Am. Chem. Soc. 2018, 140, 16015, DOI: 10.1021/jacs.8b08949.

[24] Y. Zhao, L. Guo, F. Gándara, Y. Ma, Z. Liu, C. Zhu, H. Lyu, C. A. Trickett, E. A. Kapustin, O. Terasaki, O. M. Yaghi, J. Am. Chem. Soc. 2017, 139, 13166, DOI: $10.1021 /$ jacs.7b07457.

[25] Z. Wang, A. Blaszczyk, O. Fuhr, S. Heissler, C. Wöll, M. Mayor, Nat Commun. 2017, 8, 14442, DOI: $10.1038 /$ ncomms 14442 .

[26] U. Lewandowska, W. Zajaczkowski, S. Corra, J. Tanabe, R. Borrmann, E. M. Benetti, S. Stappert, K. Watanabe, N. A. K. Ochs, R. Schaeublin, C. Li, E. Yashima, W. Pisula, K. Müllen, H. Wennemers, Nat. Chem. 2017, 9, 1068, DOI: 10.1038 /NCHEM.2823.

[27] U. Lewandowska, W. Zajaczkowski, L. Chen, F. Bouillière, D. Wang, K. Koynov, W. Pisula, K. Müllen, H. Wennemers, Angew. Chemie Int. Ed. 2014, 53, 12537, DOI: 10.1002/anie.201408279.

[28] U. Lewandowska, W. Zajaczkowski, W. Pisula, Y. Ma, C. Li, K. Müllen, H. Wennemers, Chem. Eur. J. 2016, 22, 3804, DOI: 10.1002/chem.201504952.

[29] U. Lewandowska, S. Corra, W. Zajaczkowski, N. A. K. Ochs, M. S Shoshan, J. Tanabe, S. Stappert, C. Li, E. Yashima, W. Pisula, K. Müllen, H. Wennemers, Chem. Eur. J. 2018, 24, 12623, DOI: 10.1002/chem. 201801545.

[30] P. Wilhelm, B. Lewandowski, N. Trapp, H. Wennemers, J. Am. Chem. Soc. 2014, 136, 15829, DOI: $10.1021 /$ ja507405j.

[31] P. Jonkheijm, P. van der Schoot, A. P. H. Schenning, E. W. Meijer, Science 2006, 313, 80, DOI: 10.1126/science. 1127884 